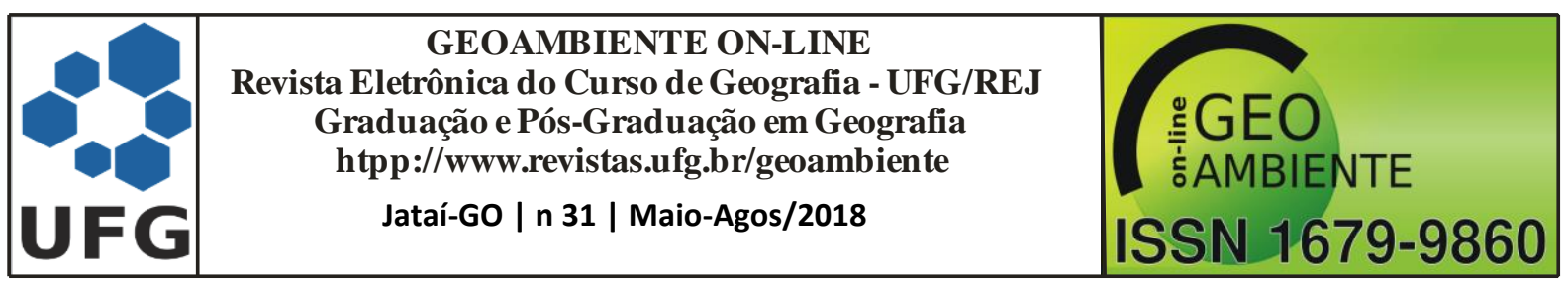

\title{
O COMPLEXO SOJA E O QUADRO NATURAL DE MATO GROSSO DO SUL: CARACTERÍSTICAS NATURAIS E CENTRALIDADE DO CULTIVO
}

\author{
Ana Carolina Torelli Marquezini Faccin \\ Geógrafa e professora colaboradora do curso de Geografia da UEMS/Campo Grande \\ caroltorelli.faccin@gmail.com
}

Resumo: O famigerado complexo soja é central para a economia do Brasil e para o estado de Mato Grosso do Sul. A leguminosa, através de melhoramento genético, se adaptou ao Cerrado brasileiro e às características naturais deste estado brasileiro, fundamentais para o sucesso da sojicultura nas últimas décadas. Neste artigo revisamos os pontos principais da estrutura produtiva da soja em Mato Grosso do Sul e de seu quadro natural, abordando assim seu modelo agrícola, sua estrutura fundiária, uso e ocupação, clima, tipos de solo e potencialidades agrícolas. Nesse ínterim, chegamos ao estabelecimento do "calendário da soja", uma sistematização metodológica que revela o poder e centralidade deste cultivo para a dinâmica de vários municípios sul-mato-grossenses. O calendário da soja, além dos períodos de plantio, colheita e vazio sanitário, abrange também os períodos de compra, venda, entrega e remuneração da soja. Essas etapas movimentam diretamente os núcleos urbanos dos municípios envolvidos com o cultivo de soja, ordenando inúmeras atividades e movimentando a vida econômica dos lugares.

Palavras-chave: Soja; especialização produtiva; Mato Grosso do Sul.

\section{THE SOYBEAN COMPLEX AND THE NATURAL FRAMEWORK OF MATO GROSSO DO SUL: NATURAL CHARACTERISTICS AND CULTIVATION CENTRALITY}

Abstract: The soybean complex is central to the brazilian economy and to the state of Mato Grosso do Sul. The legume, through genetic improvement, has adapted to the Brazilian Cerrado and to the natural characteristics of this brazilian region, fundamental for the success of soybeans in the last decades. In this article we review the main points of the soy production

\footnotetext{
Artigo recebido para publicação em 09 de Maio de 2018

Artigo aprovado para publicação em 15 de Agosto de 2018
} 


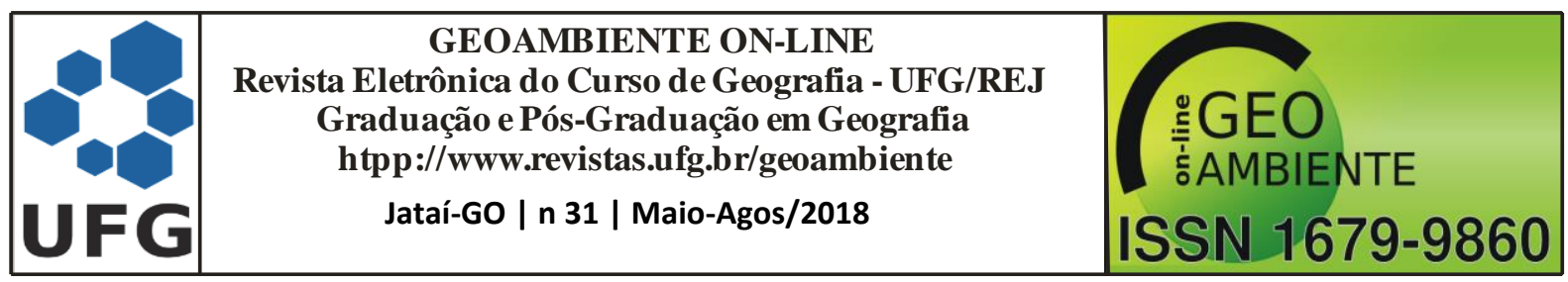

structure in Mato Grosso do Sul and its natural context, thus addressing its agricultural model, its land structure, use and occupation, climate, soil types and agricultural potentialities. In the meantime, we arrived at the establishment of the "soybean calendar", a methodological systematization that reveals the power and centrality of this crop to the dynamics of several municipalities in south-Mato Grosso. The soybean calendar, in addition to the planting, harvesting and sanitary periods, also covers the periods of purchase, sale, delivery and remuneration of soybeans. These stages directly move the urban nuclei of the municipalities involved in the soybean cultivation, ordering innumerable activities and moving the economic life of the places.

Keywords: Soybean; productive specialization; Brazil.

\section{EL COMPLEJO SOJA Y EL CUADRO NATURAL DE MATO GRUESO DEL SUR: CARACTERÍSTICAS NATURALES Y CENTRALIDAD DEL CULTIVO}

Resumen: El conocido complejo soja es central para la economía de Brasil y para el estado de Mato Grosso do Sul. La leguminosa, a través de mejoramiento genético, se adaptó al Cerrado brasileño ya las características naturales de este estado brasileño, fundamentales para el éxito de la soja en las últimas décadas. En este artículo revisamos los puntos principales de la estructura productiva de la soja en Mato Grosso do Sul y de su cuadro natural, abordando así: modelo agrícola, estructura agraria, uso y ocupación, clima, tipos de suelo y potencialidades agrícolas. En el ínterin, llegamos al establecimiento del "calendario de la soja", una sistematización metodológica que revela el poder y centralidad de este cultivo para la dinámica de varios municipios sur-mato-grossenses. El calendario de la soja, además de los períodos de siembra, cosecha y vacío sanitario, abarca también los períodos de compra, venta, entrega y remuneración de la soja. Estas etapas impulsan directamente los núcleos urbanos de los municipios involucrados con el cultivo de soja, ordenando innumerables actividades y moviendo la vida económica de los lugares.

Palabras-clave: Soja; especialización productiva; Brasil.

\section{INTRODUÇÃO}

A centralidade do complexo soja na agropecuária, na política e na economia brasileira, de maneira geral, se deve, em parte, à versatilidade do grão e a infinidade de resultados de seu processamento. Deste complexo derivam inúmeros produtos, desde alimentação humana e 


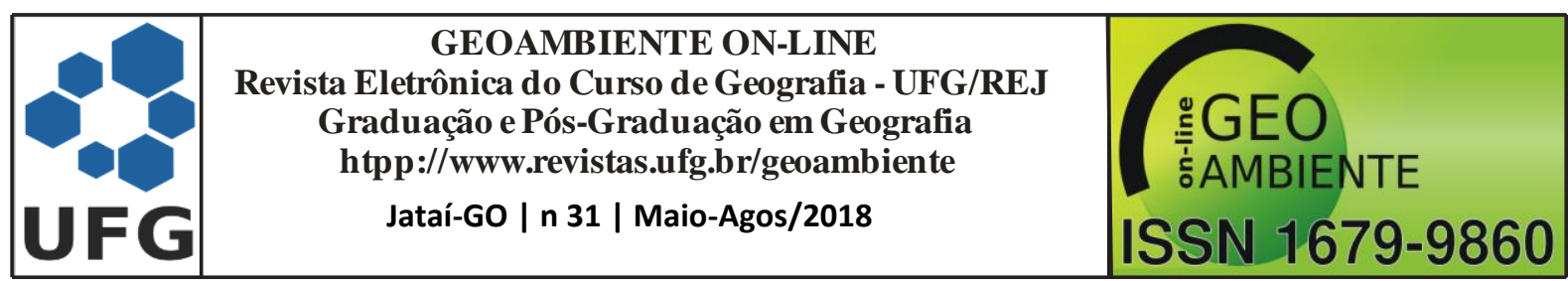

animal até fabricação de óleos para indústrias e, mais recentemente, devido aos avanços tecnológicos, em biocombustível, conforme a Figura 1 procura demonstrar.

Figura 1. Os produtos derivados da soja.

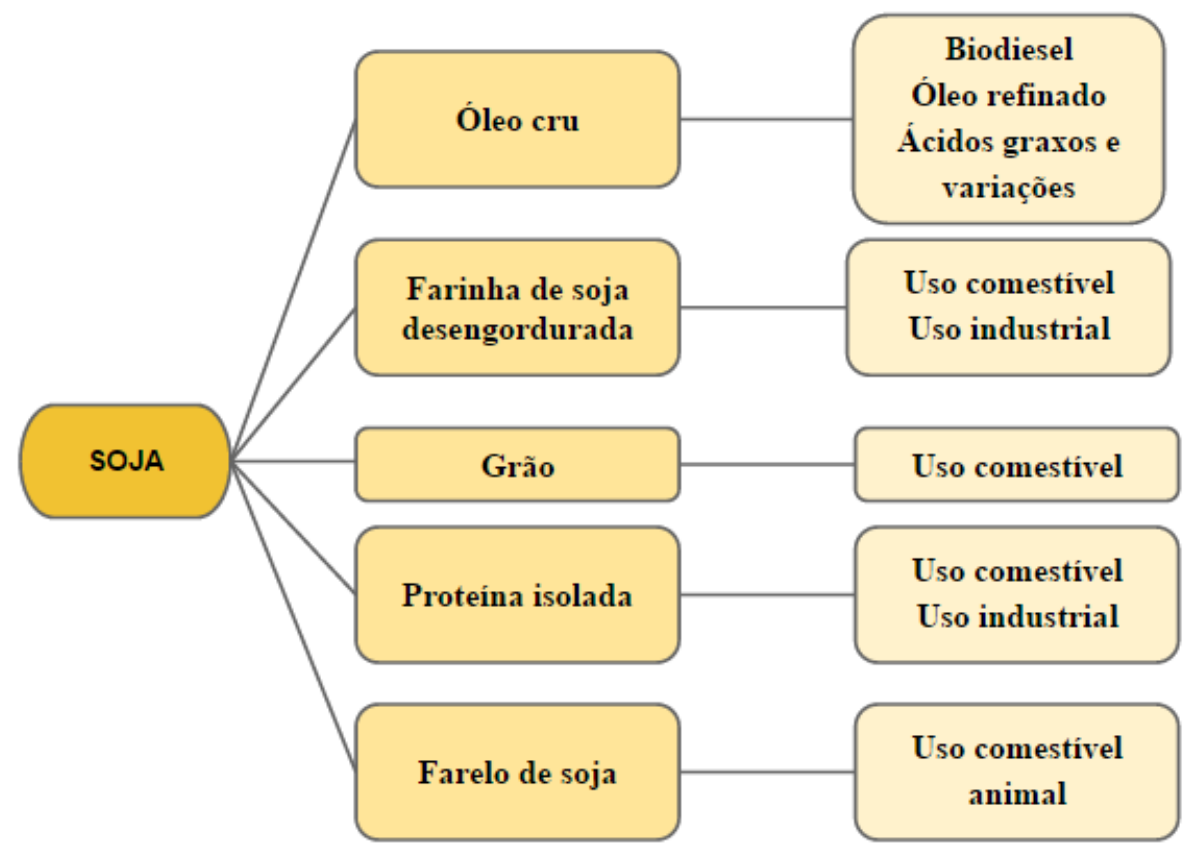

Fonte: EMBRAPA (2015). Organizado pela autora.

Como anunciava Oliveira, "a solidez do complexo soja sempre esteve associada à sua versatilidade e capacidade de reação às necessidades impostas" (OLIVEIRA, 2003, p. 59). Desse modo, o armazenamento e processamento da soja também explicita o caráter versátil da cultura pois, levando-se em conta padrões aceitáveis de temperatura e umidade, a soja pode ser transportada e processada longe do local de produção, sendo um fator que contribui para sua grande expansão no território brasileiro, especialmente em áreas de fronteira agrícola, onde a estrutura de armazenamento é tida como insuficiente para fazer frente ao grande volume produzido.

Tais características explicam a grande inserção da soja nos cerrados brasileiros e em regiões como o Centro-Oeste, onde o impacto de sua produção é profundo, capaz de apagar da paisagem muitos vestígios de estruturas produtivas anteriores. A adaptação do plantio em clima tropical, por sua vez, estabeleceu a rotação de cultura com o milho, gerando uma entressafra altamente produtiva. Ao contrário de outras culturas, como a cana-de-açúcar e o eucalipto, a rotação de cultura anual da soja com o milho recupera os nutrientes do solo e diminui os custos 


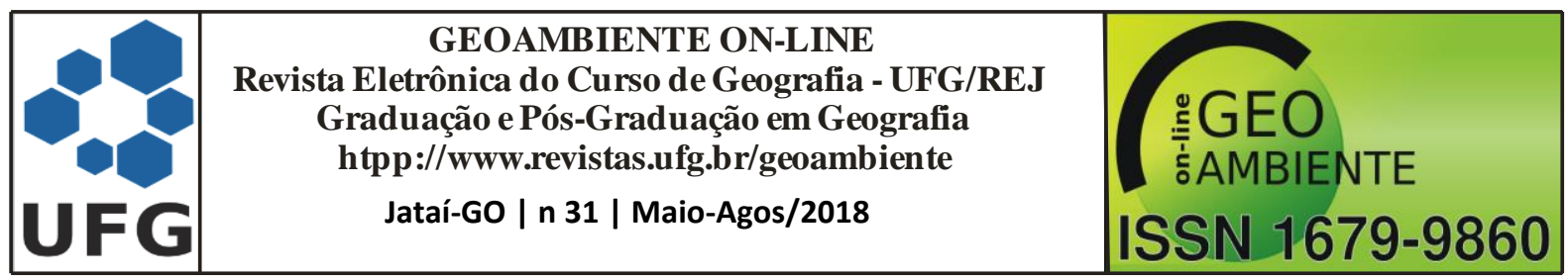

de produção, sendo mais um fator para sua expansão bem-sucedida na macrorregião CentroOeste.

Esse conjunto de vantagens promoveu o desenvolvimento de toda uma cadeia produtiva da soja (Figura 2), gerando investimentos privados e públicos em estruturas de armazenagem, unidades de processamento do grão e escoamento e exportação da soja e subprodutos.

Figura 2. Destino do agronegócio brasileiro de soja, 2013.

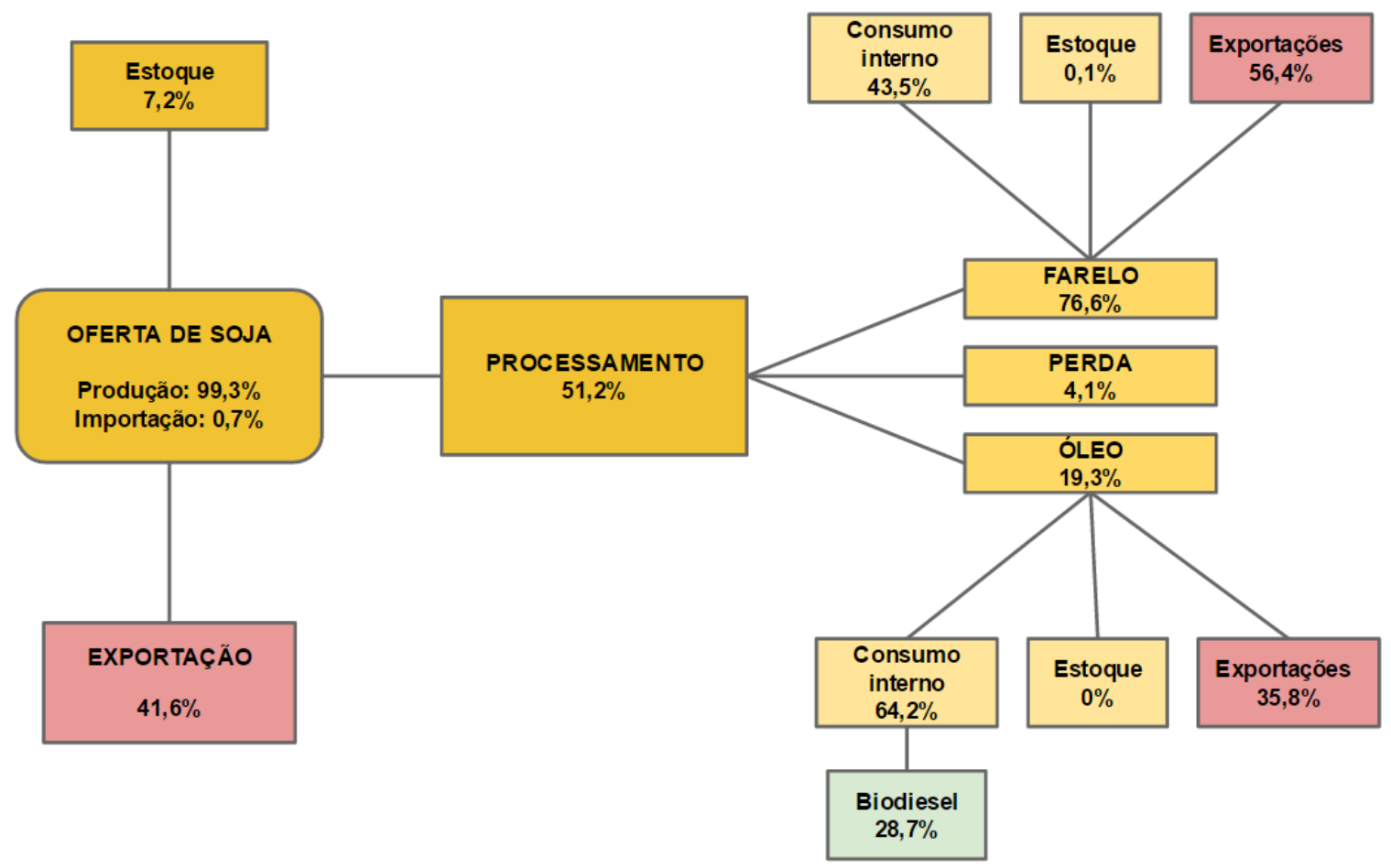

Fonte: EMBRAPA (2015). Organizado pela autora.

Levando-se em conta o momento atual brasileiro, que apresenta indícios de desindustrialização da economia, o modelo agrário-exportador, pautado em commodities agrícolas encontra-se cada vez mais fortalecido.

Assim, o agronegócio se mantém fundamental para a economia brasileira, e as últimas décadas denotam um esforço intenso de modernização da prática agrícola, seja para maior produção e rendimento, seja para elevar os níveis de competitividade do setor, adequando a situação brasileira a parâmetros mundiais. A soja, em particular, influencia significativamente a economia brasileira e tem o poder de reorganizar o território para maior fluidez no escoamento de seus subprodutos. 


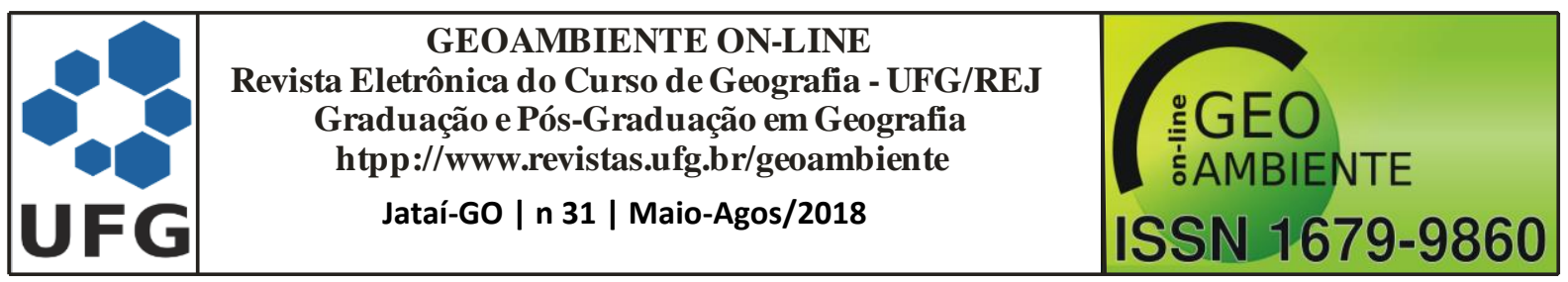

Nenhuma cultura renovou os instrumentos e os meios de trabalho; não transformou os métodos de produção nem engendrou conhecimentos técnicos e científicos com tamanha velocidade; nenhum reconheceu de forma tão acentuada a superioridade dos métodos e processos modernos como elementos propulsores do progresso da agricultura; como, também, nenhuma cultura abriu trincheiras para a "indústria da agricultura", quanto a cultura da soja, na história do Brasil. Por isso, detalhar a sua participação na história da modernização do campo brasileiro é um imperativo, para entendermos a ocupação do espaço pela agroindústria esmagadora da soja (OLIVEIRA, 2003, p. 59).

Nesse contexto, devemos salientar o interesse das corporações transnacionais em investir de maneira intensa na produção em larga escala dos mais diversos tipos de flex-crops e commodities. A competição instalada mundialmente pelo controle de terras e pelo controle da produção, seja através da atuação de tradings agrícolas, seja através das práticas de land grabbing (BORRAS JR et al, 2014) vem gerando fortes implicações para os países periféricos, especialmente para o Brasil.

Segundo Oliveira (2003) a soja praticamente é a cultura responsável por determinar a verdadeira inserção do Mato Grosso do Sul no modo de produção capitalista, sendo que sua presença, segundo o referido autor, foi capaz até mesmo de estimular e expandir o modo de produção para a pecuária, atividade mais tradicional do estado, além de outros circuitos produtivos.

Compreender a interação da soja com outras culturas e atividades produtivas no estado, principalmente no que se refere à suposta competição por área, é fundamental para que um entendimento mais completo seja atingido; para tanto, é necessário compreender os fatores que possibilitaram o sucesso do cultivo da soja no Cerrado e, em particular, no território sul-matogrossense.

\section{Mato Grosso do Sul no período atual: crescente especialização produtiva}

Historicamente, a estrutura fundiária do estado de Mato Grosso do Sul sempre foi caracterizada pela presença de grandes propriedades rurais, o que é um fator importante para o sucesso da produção de monoculturas em larga escala. Pouco mudou no estado durante a transição de uma economia agropastoril para uma economia baseada na agroindústria: grandes porções de terras nas mãos de poucos geram uma concentração de riqueza e domínio dos meios de produção; consequentemente, a concentração fundiária é evidente no território sul-matogrossense (Figura 3). 


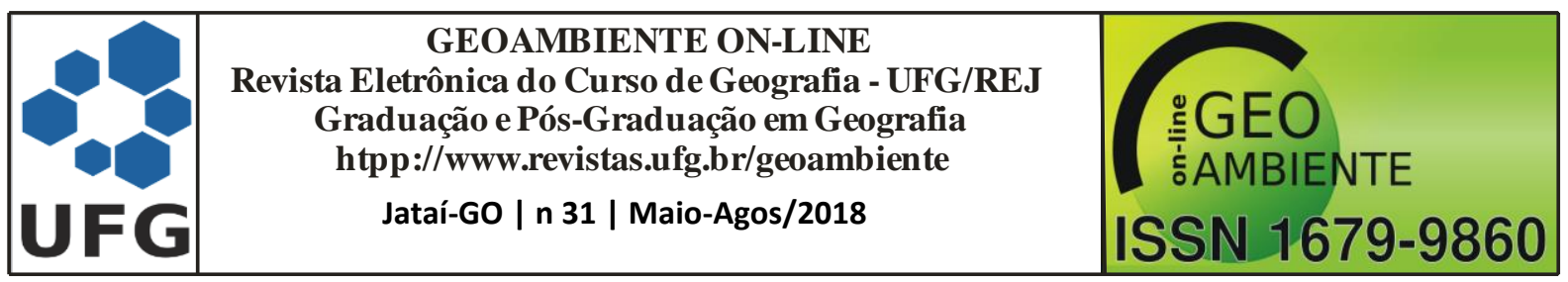

Figura 3. Mato Grosso do Sul. Imóveis certificados privados, 2015.

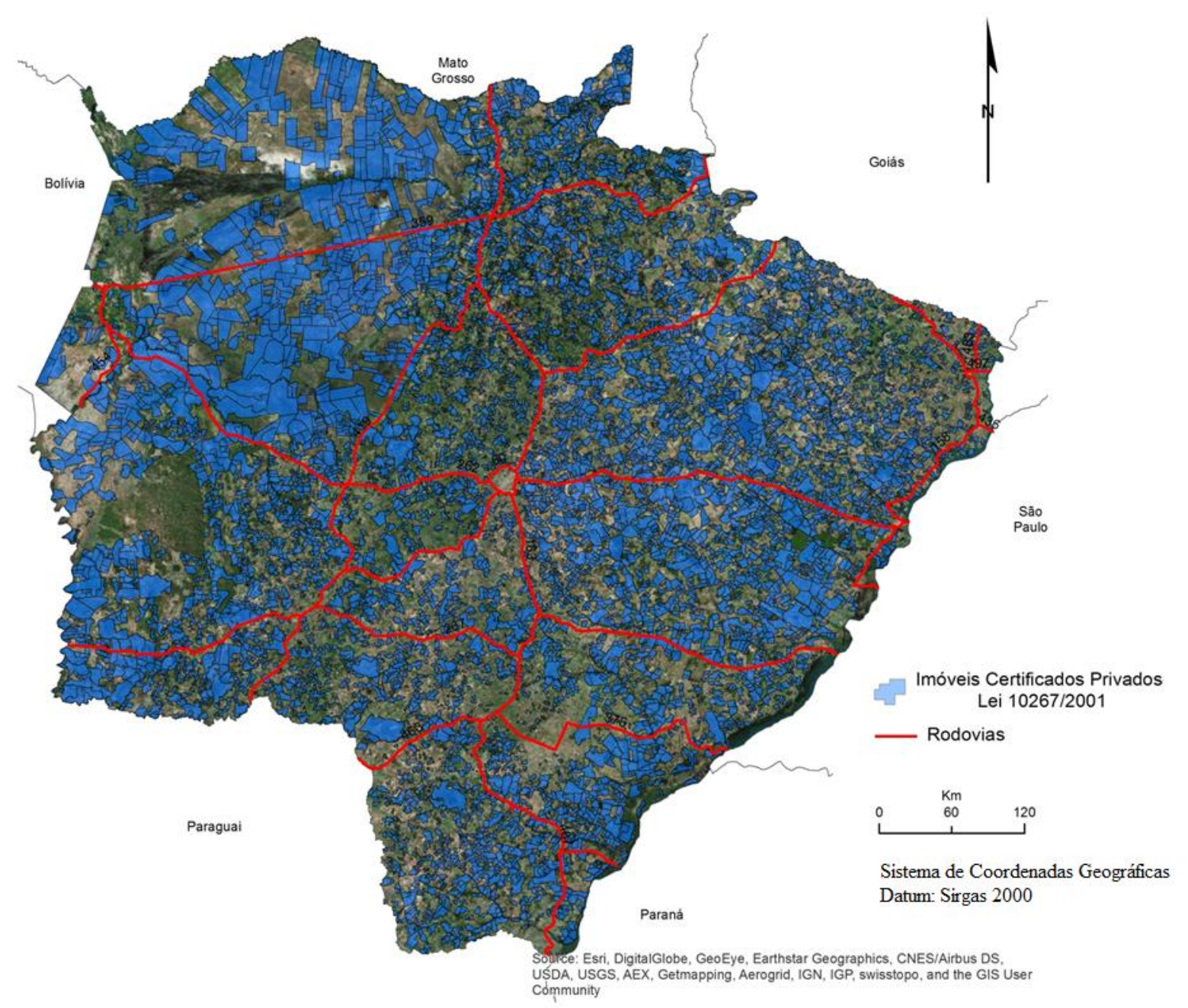

Fonte: INCRA (2014). Organizado pela autora

A estrutura fundiária baseada em grandes propriedades é um fato recorrente em todas as regiões do estado, notadamente na região pantaneira, porção noroeste do estado, tradicionalmente envolvida com atividades de extração mineral e pecuária.

O início do cultivo de soja (juntamente com o trigo e o arroz) se deu de modo inovador em meados dos anos 1970 (ARANTES \& SOUZA, 1993), com a implantação, no então sul de Mato Grosso" (área também denominada à época de "terras de Campos de Vacaria"), de empresas agrícolas lideradas por lavradores do Rio Grande do Sul (de onde se originou esse modelo de empresa no Brasil). As atividades se processavam com grande emprego de tecnologia e financiamento via Banco do Brasil, condicionado a "exigências de análise de solo, de colheita mecanizada e de emprego de sementes selecionadas" (IBGE, 1977 apud ARANTES

\footnotetext{
${ }^{1}$ Mato Grosso do Sul foi emancipado do estado de Mato Grosso em 1 de janeiro de 1979.
} 


\begin{tabular}{|c|c|c|}
\hline & $\begin{array}{c}\text { GEOAMBIENTE ON-LINE } \\
\text { Revista Eletrônica do Curso de Geografia - UFG/REJ } \\
\text { Graduação e Pós-Graduação em Geografia } \\
\text { htpp://www.revistas.ufg.br/geoambiente } \\
\text { Jataí-Go | n } 31 \text { | Maio-Agos/2018 }\end{array}$ & $\begin{array}{c}\text { ISSN 1679-9860 } \\
\text { G }\end{array}$ \\
\hline
\end{tabular}

\& SOUZA, 1993, p. 30), sendo que "a expansão dos cultivos mecanizados de trigo e soja se deram em terras adquiridas pelos gaúchos, dos fazendeiros mato-grossenses, por preços inferiores aos do arrendamento de terra nas suas áreas de procedência" (ARANTES \& SOUZA, 1993, p. 30).

Diante dessa situação, o uso e ocupação (terminologia do IBGE) atuais do estado de Mato Grosso do Sul seguem com o espaço majoritariamente sendo ocupado por pastagens e lavouras, em relação a outros usos (Figura 4).

Figura 4. Mato Grosso do Sul. Uso e ocupação, 2015.
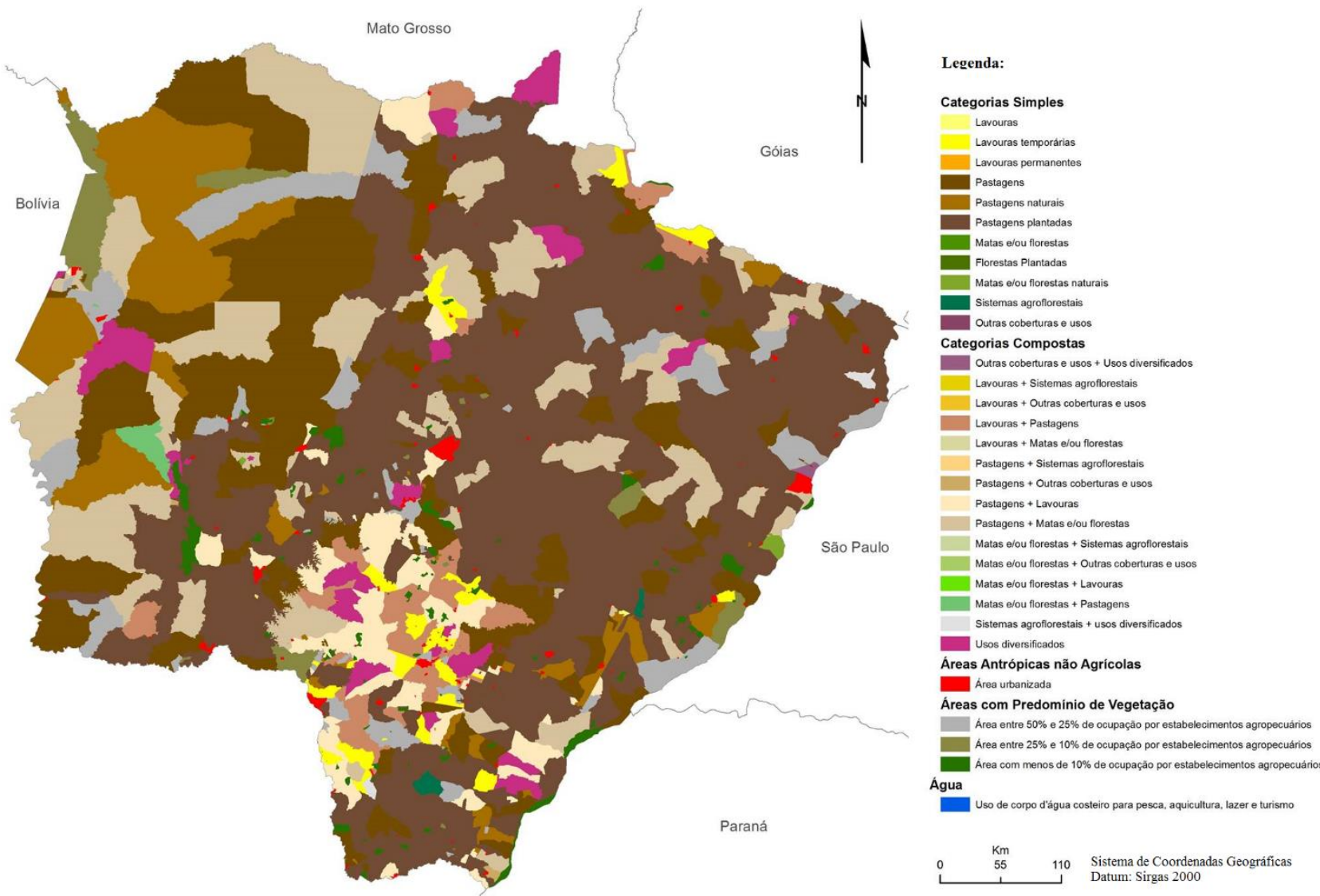

Fonte: IBGE (2015). Organizado pela autora

A região de Dourados é a que apresenta maior concentração de diferentes atividades, à primeira vista; porém, uma análise detalhada revela que as áreas são ocupadas em sua maioria por diversas classes de lavouras (entre temporárias e permanentes e com presença de pastagem), que dividem o espaço com pontos isolados de matas e sistemas agroflorestais. Todo o conjunto composto por clima, solos, vegetação e relevo sul-mato-grossenses apresenta características particulares, entre elas, 


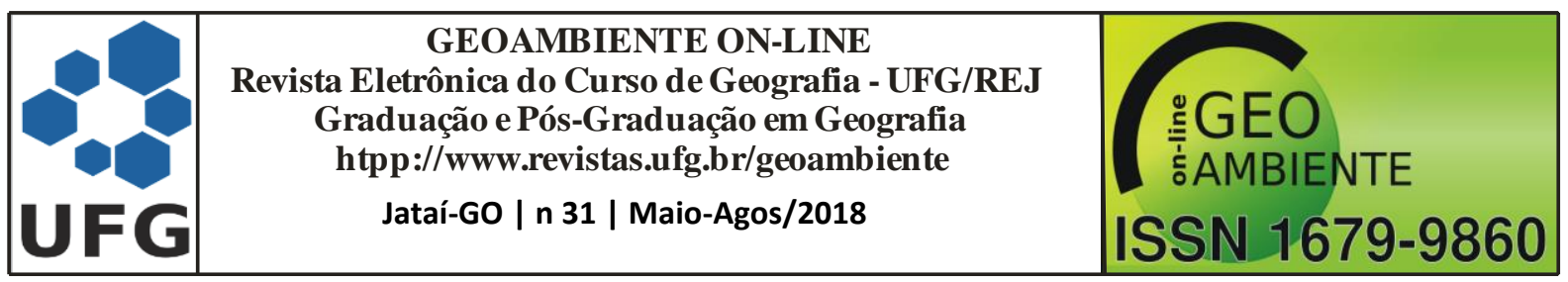

um clima semiúmido com verões (novembro a março) chuvosos e invernos (abril a setembro) secos; solos, em maioria, latossolo (vermelho e roxo), areias quartznosas e podzólico; e ainda, três regiões fitoecológicas sendo definidas em maior parte cerrado (+ de 80\%), vegetação charquenha e floresta estacional (semidecidual e decidual), consolidam uma paisagem benéfica à agricultura - e por ter terreno plano, altamente mecanizada (OLIVEIRA, 2003, p. 27).

O bioma Cerrado, em se tratando de clima, tipos de solo e potencial agrícola (figuras 5, 6 e 7pode ser considerado muito receptivo à implantação da agricultura intensiva em larga escala, podendo-se facilmente corrigir a inadequação de alguns fatores, como a elevada acidez do solo.

A maioria dos solos sob vegetação de cerrados tem sido diagnosticada como de baixa fertilidade natural. Menos de $2 \%$ da área é representada por solos eutróficos. Para que ocorra o uso intensivo destes solos de baixa fertilidade, com cultivos anuais, há a necessidade de se construir a fertilidade dos mesmos, pela adição de fertilizantes e corretivos. A perda por erosão nestes solos com "fertilidade construída" é economicamente mais grave do que em solos onde tais investimentos não são necessários (ARANTES \& SOUZA, 1993, p. 72).

Figura 5. Mato Grosso do Sul. Tipos de clima, 2015.

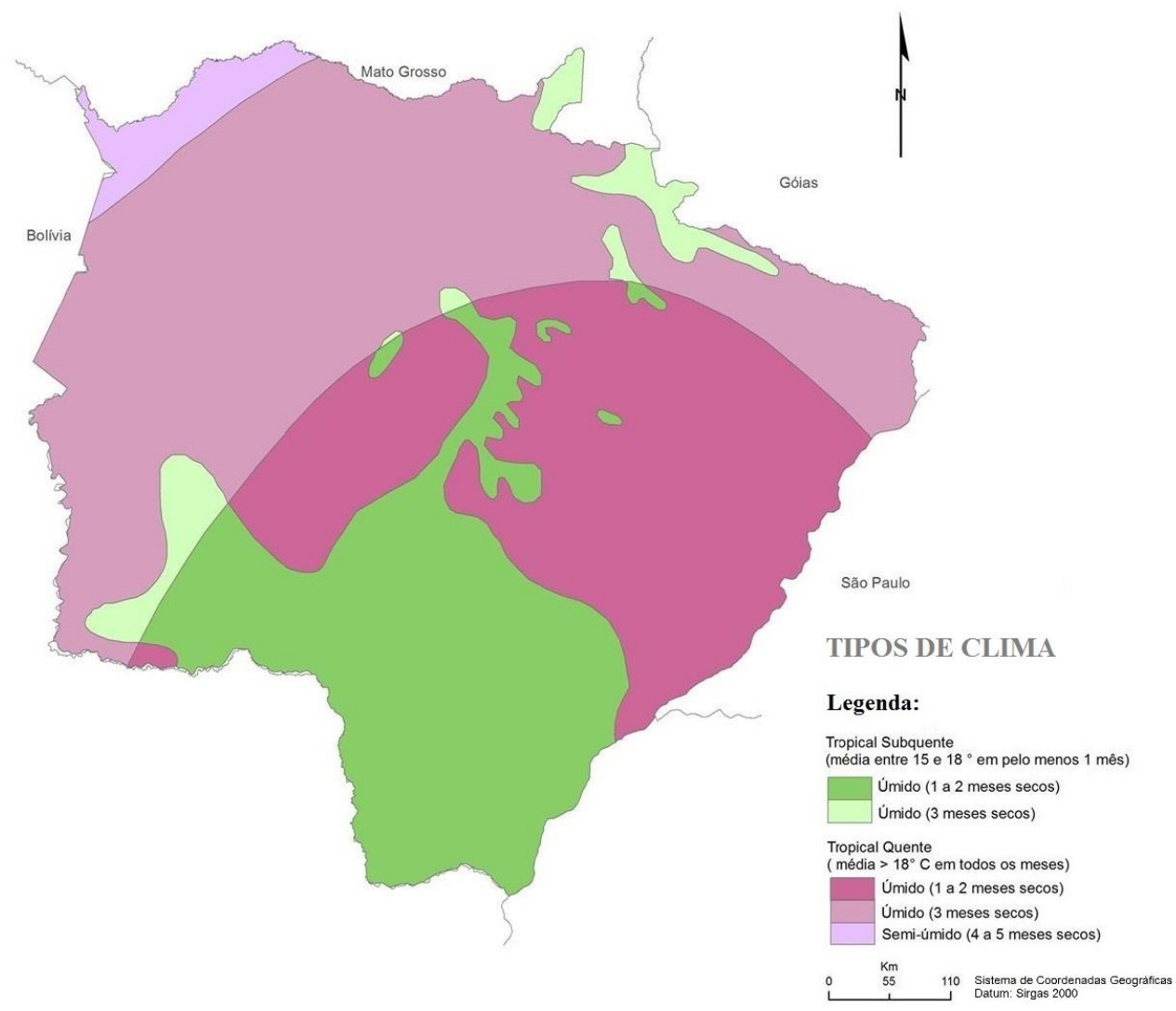

Fonte: IBGE (2015). Organizado pela autora. 


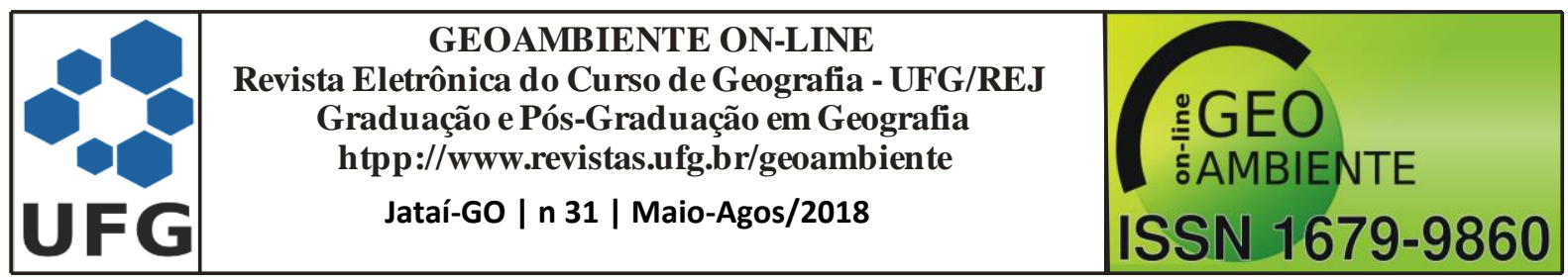

Figura 6. Mato Grosso do Sul. Tipos de solo, 2015

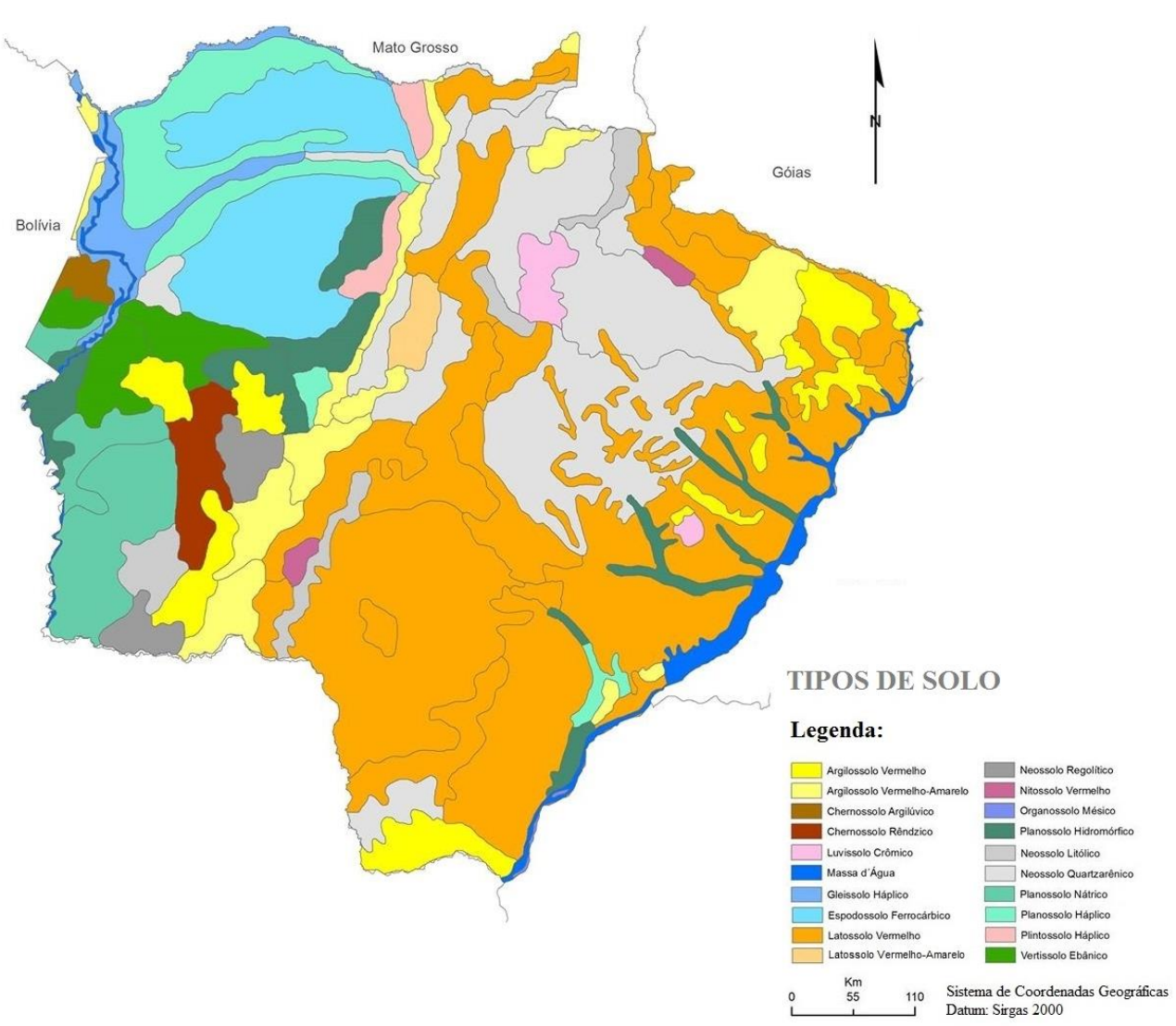

Fonte: IBGE (2015). Organizado pela autora

A formação pedológica sul-mato-grossense caracteriza-se em grande parte do estado (excetuando-se a região pantaneira) pela presença massiva de latossolo vermelho, muito comum nas regiões Centro-Oeste, Sul e Sudeste do País. São corresponsáveis pelo sucesso da produção de grãos nessas localidades, pois ocorrem em áreas de "relevo plano e suave ondulado, propiciando a mecanização agrícola” (AGEITEC/EMBRAPA, 2017).

Diante desse contexto altamente dependência de condições naturais, o clima é considerado o mais importante fato que desafia o rendimento médio das lavouras; irregularidades no regime de chuvas, por exemplo, são consideradas o fator que mais preocupa o produtor rural, seja ele pequeno, médio ou grande. 


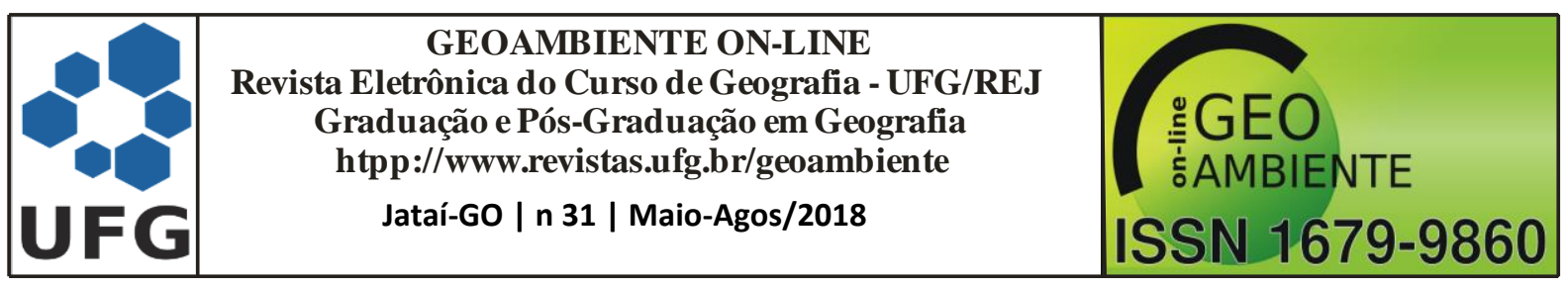

Figura 7. Mato Grosso do Sul. Potencial agrícola, 2015

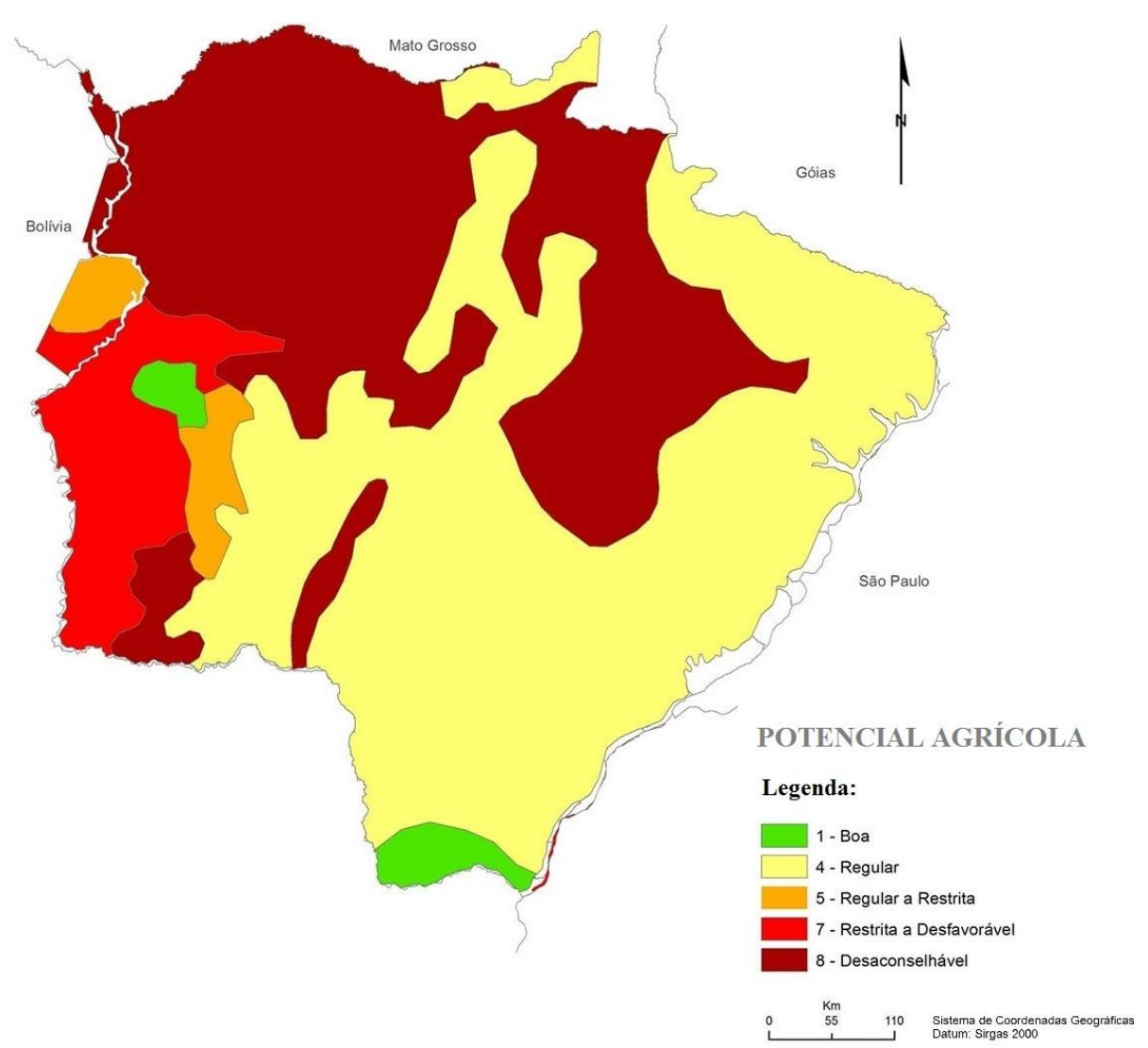

Fonte: IBGE (2015). Organizado pela autora

\section{O calendário da soja em Mato Grosso do Sul}

A dinâmica das lavouras de soja tem implicações profundas nos núcleos urbanos dos municípios produtores. Há uma racionalização do cultivo que podemos chamar de "calendário da soja" (Figura 8). Este rege não somente os circuitos de insumos, maquinários, armazenagem e movimentação dos grãos, mas também influencia fortemente outros circuitos relacionadas com a soja. A sojicultura, juntamente com o plantio do milho safrinha, também cria circuitos locais de abastecimento, que envolvem fortemente a pecuária, especialmente a praticada pelos pequenos produtores, por exemplo. O farelo de soja é utilizado como um importante complemento para a alimentação do gado e seu preço influencia diretamente os custos de manutenção do rebanho e o lucro final dos pequenos pecuaristas. 


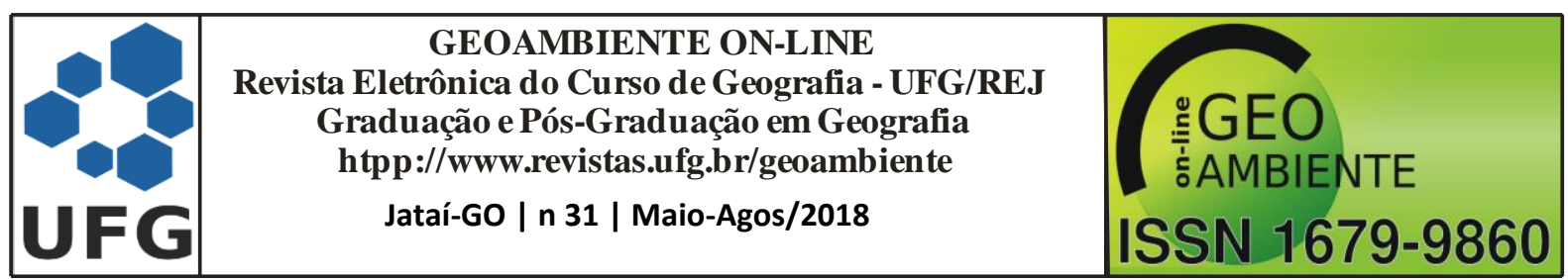

Figura 8. Mato Grosso do Sul. Calendário da soja, 1970-1990 (período do trigo safrinha) e 1990-2017 (período do milho safrinha).
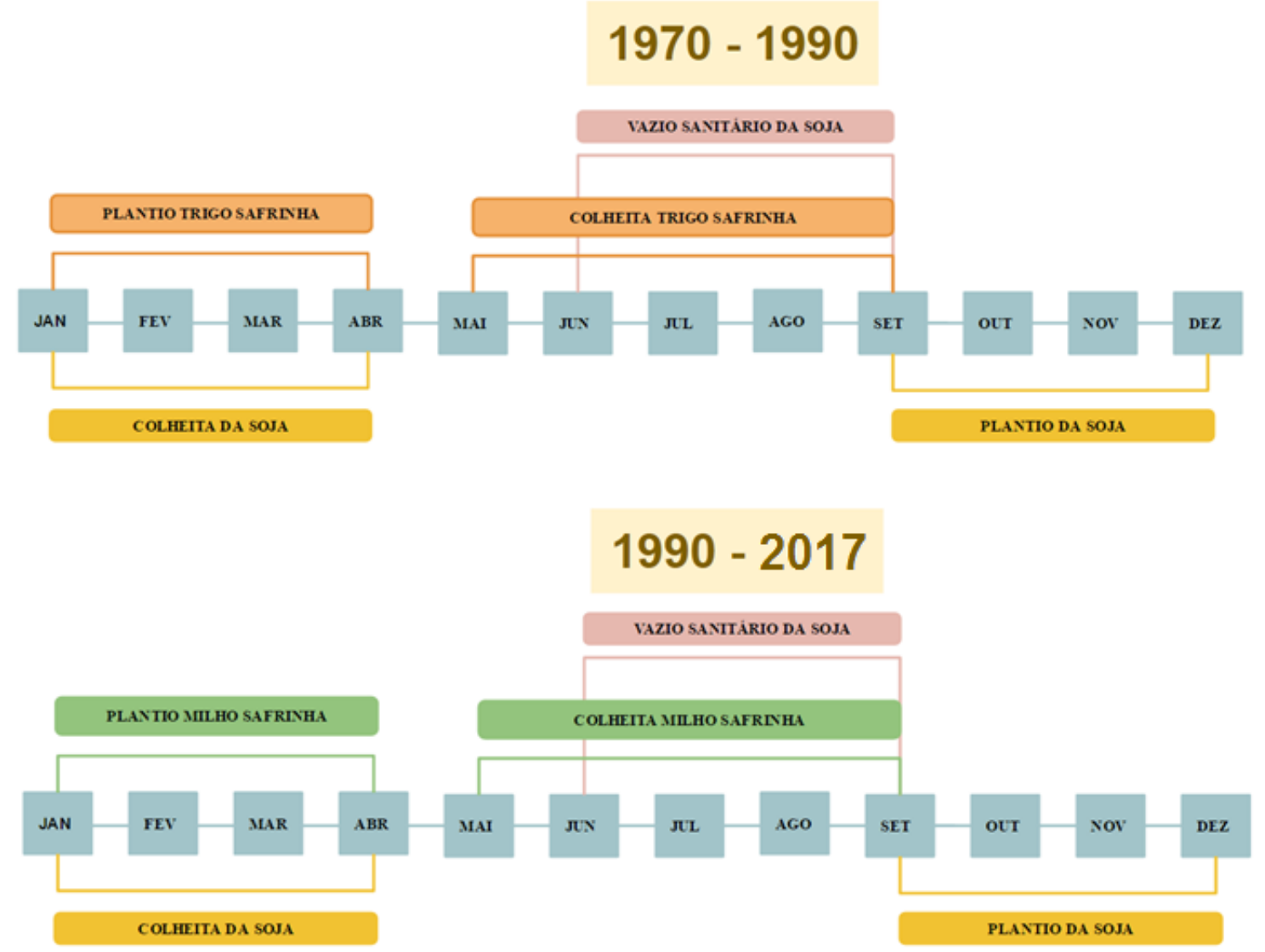

Fonte: Diversas fontes ${ }^{2}$. Organizado pela autora.

O calendário da soja (Figura 8, período 1990-2017) identifica o período de plantio e colheita da soja e do milho safrinha, assim como também indica o período de vazio sanitário adotado em virtude da proteção contra pragas, especialmente contra a ferrugem asiática. $\mathrm{O}$ período de vazio sanitário é adotado por vários estados produtores de soja, situação que a EMBRAPA nomeia como "consórcio anti-ferrugem asiática” (gráfico 1).

Uma proposta futura, que vem sendo testada na região norte de Mato Grosso do Sul, nas safras 2014/2015 e 2015/2016, aponta uma possível substituição do milho safrinha pela "soja safrinha", o que retiraria o Mato Grosso do Sul do consórcio anti-ferrugem asiática vigente.

A alternativa de sucessão de plantio, fortemente desencorajada pela Embrapa (EMBRAPA, 2015), tem sido testada na região de São Gabriel D’Oeste por iniciativa de produtores locais,

\footnotetext{
${ }^{2}$ Para a formulação do calendário da soja para o estado de Mato Grosso do Sul foram utilizadas diversas fontes, entre elas, informativos de associações rurais de produtores de soja/milho e reportagens televisivas.
} 


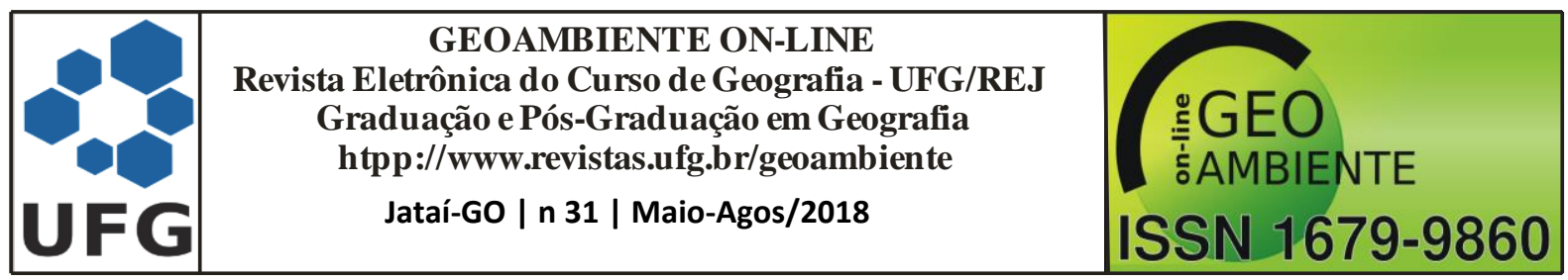

que utilizam diferentes cultivares de soja durante o período safrinha, de maio a setembro (figura 9).

Gráfico 1. Períodos de vazio sanitário, EMBRAPA, consórcio anti-ferrugem asiática.

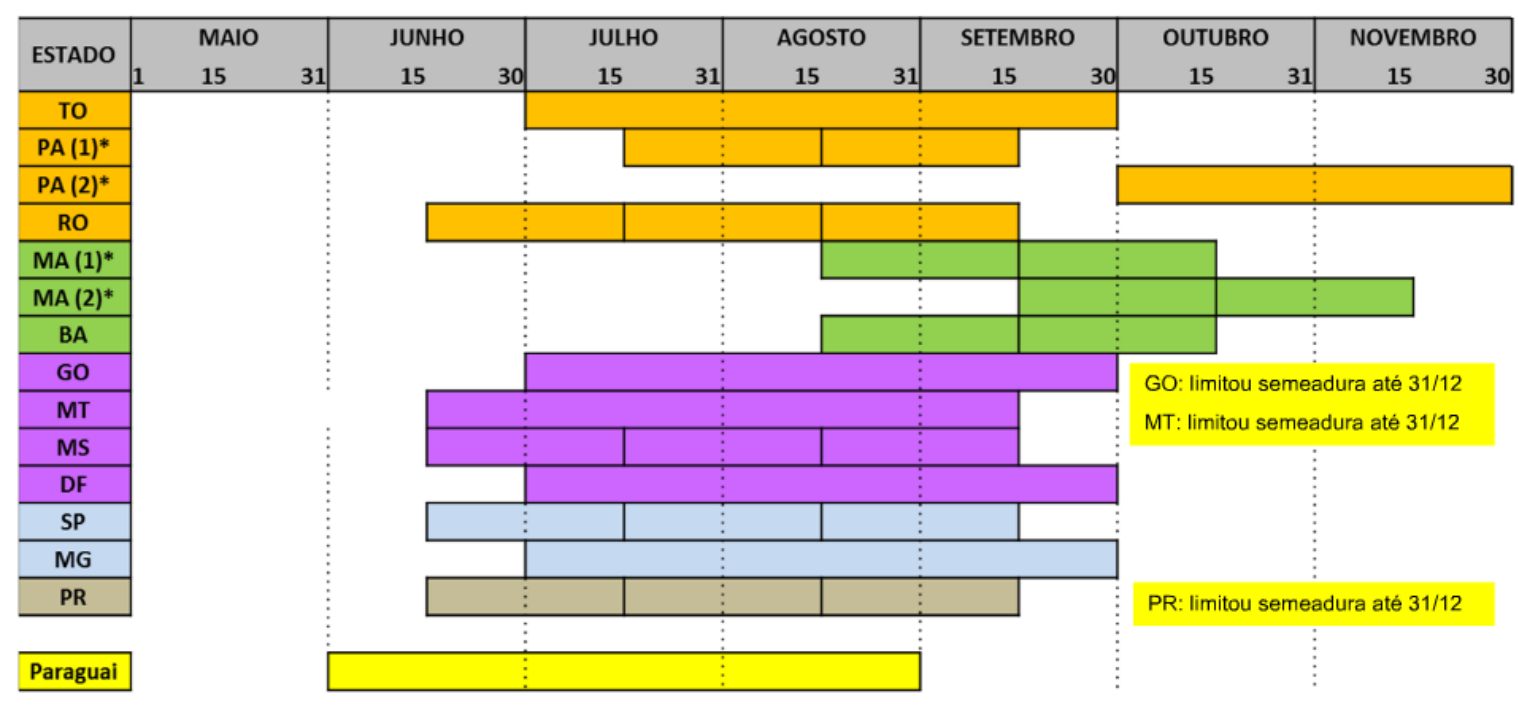

•PA (1): Microrregiôes de Conceição do Araguaia, Redenção, Itatuba, Marabá e Altamira (Distrito Castelo dos Sonhos)

*PA (2): Microrregiốes de Santarém, Paragominas, Bragantina, Guamá, Altamira (com exceção Distrito Castelo dos Sonhos)

"MA (1): Microrregiões de Alto Mearim, Grajaú, Balsas, Imperatriz e Porto Franco

"MA (2): Microrregiōes de Baixada Maranhense, Caxias, Chapadinha, Codó, Coelho Neto, Gurupi, Itapecuru Mirim, Pindaré, Presidente Dutra, Rosário,

Paço Lumiar, Raposa São José de Ribamar, São Luís

Fonte: Embrapa (2016).

Figura 9. Mato Grosso do Sul. Proposta de futuro calendário da soja, 2016.

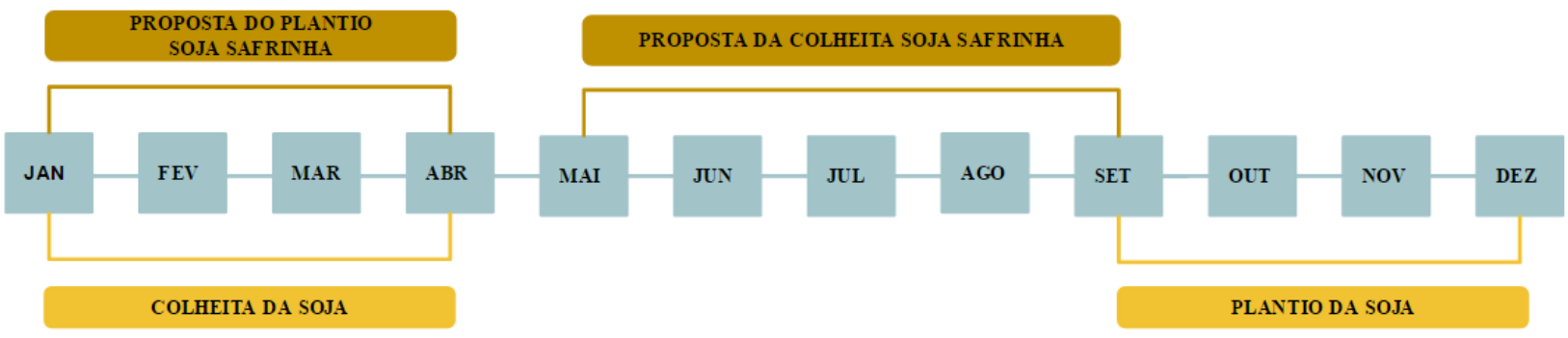

Fonte: Diversas fontes. Organizado pela autora.

Tamanha sofisticação produtiva gera uma situação territorial de extrema especialização, cuja tradução visual pode ser observada na figura 10 :

O calendário da soja, além dos períodos de plantio, colheita e vazio sanitário, abrange também os períodos de compra, venda, entrega e remuneração da soja. Essas etapas, em 


\begin{tabular}{|c|c|c|}
\hline & $\begin{array}{c}\text { GEOAMBIENTE ON-LINE } \\
\text { Revista Eletrônica do Curso de Geografia - UFG/REJ } \\
\text { Graduação e Pós-Graduação em Geografia } \\
\text { htpp://www.revistas.ufg.br/geoambiente } \\
\text { Jataí-Go | n } 31 \text { | Maio-Agos/2018 }\end{array}$ & $\begin{array}{c}\text { ISSN 1679-9860 } \\
\text { Ge }\end{array}$ \\
\hline
\end{tabular}

especial, movimentam diretamente os núcleos urbanos dos municípios envolvidos com o cultivo de soja, ordenando inúmeras atividades e movimentando a vida econômica dos lugares ${ }^{3}$.

Figura 10. Mato Grosso do Sul. Localização das lavouras de cana-de-açúcar, eucalipto e soja,

\section{$2015 / 2016$}

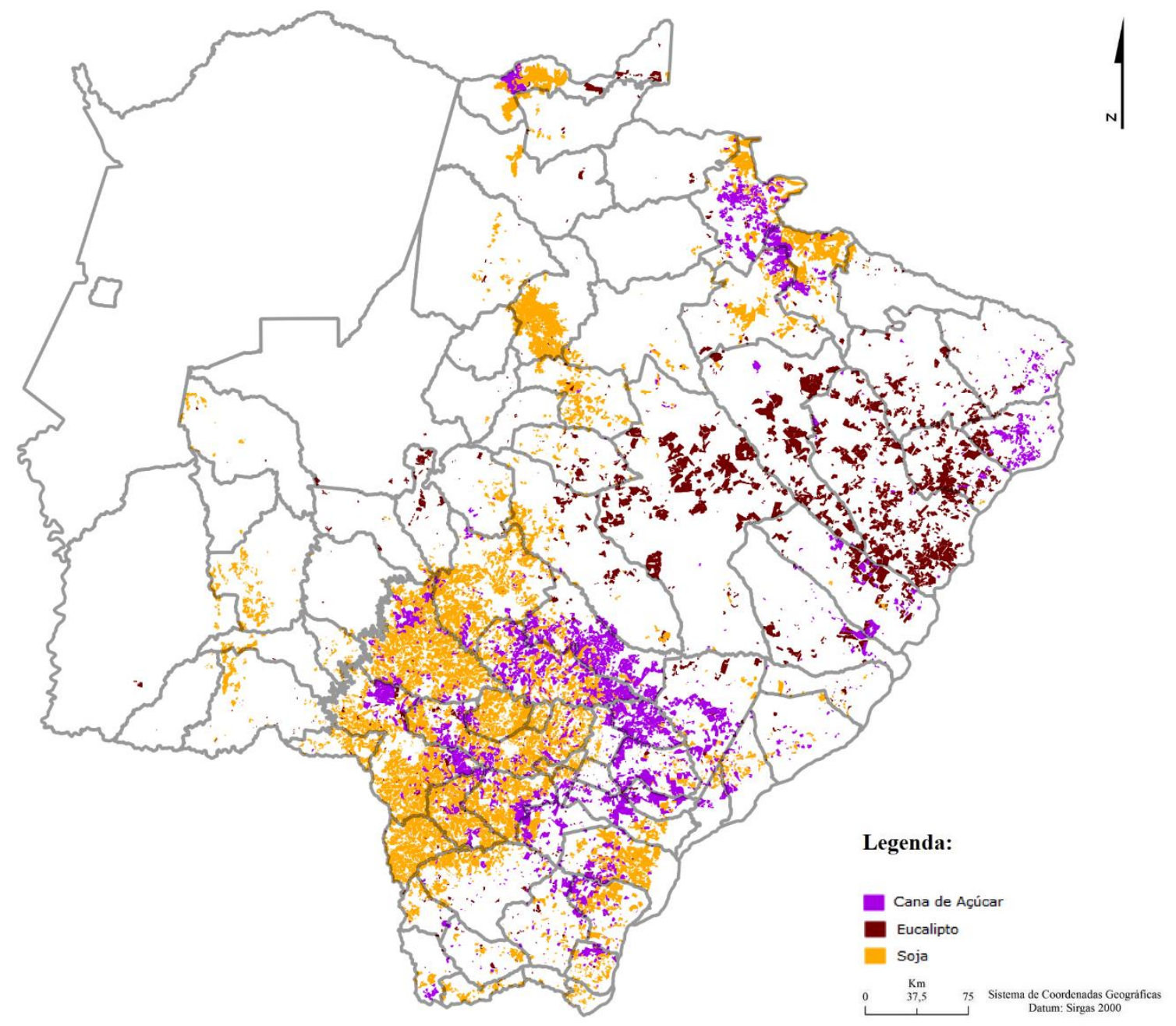

Fonte: SIGAWEB MS (2015). Organizado pela autora.

Do mesmo modo que a remuneração da soja favorece o comércio e movimenta grande parte do setor de serviços gerais prestados por particulares, situação que podemos nominar de "transferência de renda campo-cidade", a mesma cidade pode padecer caso a colheita não seja satisfatória. Teixeira (1989) já antevia que a soja, enquanto mercadoria, se introduzia em Mato

\footnotetext{
${ }^{3}$ Realizando entrevistas nas cidades de Dourados e Ponta Porã, além de acompanhar informações veiculadas em reportagens de jornais locais, pudemos constatar que a renda de vários serviços urbanos (pedreiros, eletricistas e afins) depende diretamente da renda do campo obtida da colheita da soja; a inauguração de empreendimentos imobiliários de alto-padrão e revendas de carros também costumam ser programadas para o final da colheita da soja, pois as chances de venda são bem maiores, segundo comerciantes locais.
} 


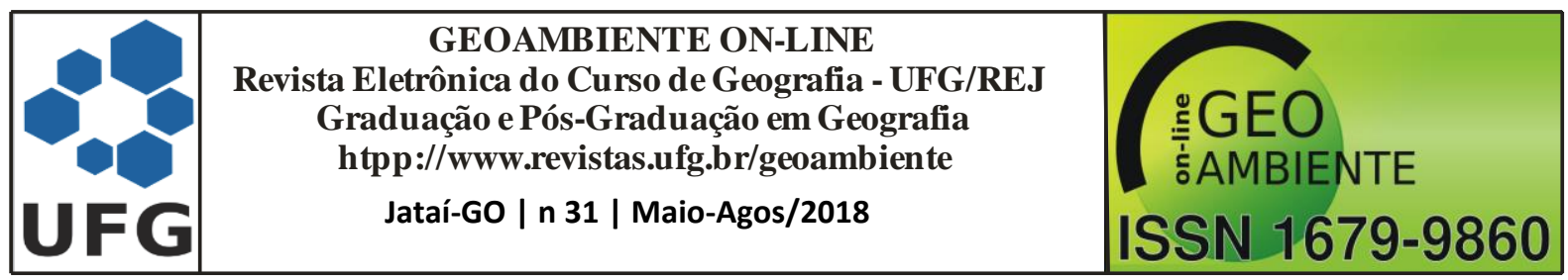

Grosso do Sul como um "fetiche", cuja presença já carregava consigo uma série de interesses, sendo esses agrícolas, industriais, comerciais, setor de serviços e avanços científicos. Juntamente com outras culturas, especialmente a cana-de-açúcar e a silvicultura da porção leste do estado, a soja equipa o território sul-mato-grossense, trazendo unidades de empresas de maquinário, insumos e comercialização de grãos, além de empresas do ramo logístico, de diversas partes do Brasil e do mundo.

\section{CONCLUSÕES}

A centralidade e importância do complexo soja para a economia brasileira e, em particular, para o estado de Mato Grosso do Sul, é inegável e buscamos através deste artigo demonstrar a associação fundamental entre o quadro natural do estado de Mato Grosso do Sul e o sucesso do cultivo desta leguminosa, levando em consideração o alto emprego de técnica para que o grão se "tropicalizasse" e conseguisse tamanha inserção no Cerrado brasileiro. Primordial para a balança comercial brasileira, infelizmente o cultivo da soja significa uma especialização produtiva cada vez mais profunda, com pleno apoio estatal (diversas escalas), o que alimenta cada vez mais a velha opção de ser um país majoritariamente agrário-exportador, pautado em commodities que se caracterizam por terem grandes volumes e carregarem baixo valor agregado. Tal situação, ligada totalmente à uma divisão internacional do trabalho, sufoca outras formas de produzir (formas que se mostrariam menos predatórias e que empregariam mais mão-de-obra local), comprometendo grandes áreas e recursos públicos, em uma lógica global que não se relaciona em nada com o lugar de produção.

\section{REFERÊNCIAS BIBLIOGRÁFICAS}

AB'SABER, A. N. Potencialidades paisagísticas brasileiras. Geomorfologia n. 55. São Paulo, Instituto de Geografia da USP, 1977.

AGEITEC - AGÊNCIA EMBRAPA DE INFORMAÇÃO TECNOLÓGICA. Solos tropicais, latosssolos vermelhos. Disponível

em: $<$ http://www.agencia.cnptia.embrapa.br/gestor/solos_tropicais/arvore/CONT000fzyjaywi02w x5ok0q43a0r9rz3uhk.html>. Acesso em: 05 fev. 2017.

ARANTES, N. E; SOUZA, P. I. M. de. Cultura da soja nos cerrados. Piracicaba: POTAFOS, 1993. $535 \mathrm{p}$.

ASSOCIAÇÃO BRASILEIRA DAS INDÚSTRIAS DE ÓLEOS VEGETAIS - ABIOVE. Estatísticas. 


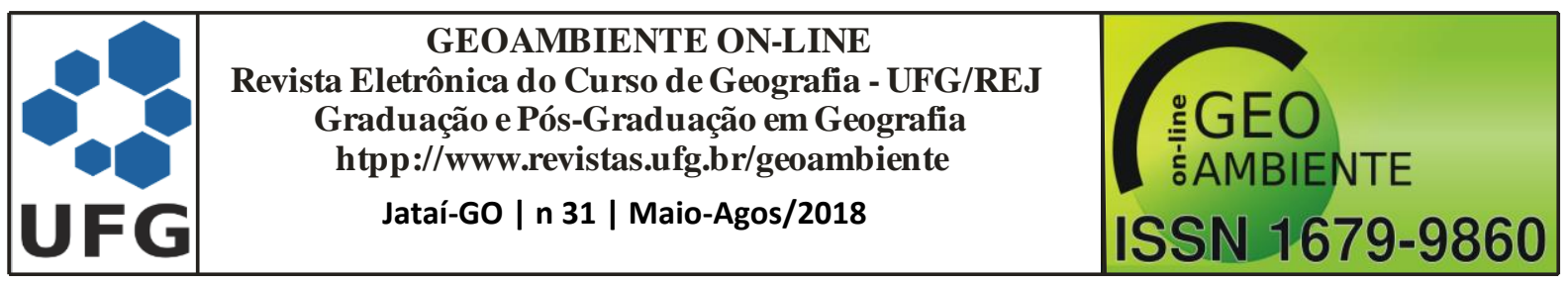

em: $<$ http://www.abiove.org.br/site/index.php?page=estatistica\&area=NC0yLTE=>. Acesso em: 05 abr. 2015.

BORRAS JR, SATURNINO M.; FRANCO, J C.; ISAKSON, R; LEVIDOW, L and VERVEST, P. Towards Understanding the Politics of Flex Crops and Commodities: Implications for Research and Policy Advocacy. Think Piece Series on Flex Crops \& Commodities. Amsterdam: Transnational Institute, 2014.

EMBRAPA - EMPRESA BRASILEIRA DE PESQUISA AGROPECUÁRIA. Comunicado técnico. Sucessão soja/soja safrinha em Mato Grosso do Sul: um modelo de produção com sustentação agronômica? Dourados, 2015. Disponível em: < https://www.infoteca.cnptia.embrapa.br/infoteca/bitstream/doc/1031726/1/COT2015206COR RIGIDO.pdf>. Acesso em: 05 jun. 2016.

EMBRAPA - EMPRESA BRASILEIRA DE PESQUISA AGROPECUÁRIA. Software Embrapa Soja. Disponível em: <https://www.embrapa.br/soja>. Acesso em: 10 fev. 2015.

INSTITUTO BRASILEIRO DE GEOGRAFIA E ESTATÍSTICA - IBGE. Produção Agrícola Municipal. Disponível em:

<http://www.ibge.gov.br/home/estatistica/pesquisas/pesquisa_resultados.php?id_pesquisa=44

>. Diversas consultas. Acesso em: 20 dez. 2016.

INSTITUTO NACIONAL DE COLONIZAÇÃO E REFORMA AGRÁRIA. Sistema de certificação de imóveis rurais, Shapefiles. Disponível em: <http://certificacao.incra.gov.br/Certifica/>. Acesso em: 20 nov. 2015.

OLIVEIRA, T. C. M. de. Agroindústria e reprodução do espaço. Campo Grande, MS: UFMS, 2003. 260 p.

SIGA WEB MS. Sistema de Informação Geográfica do Agronegócio - Mato Grosso do Sul. Disponível em: < http://104.236.254.167/ms/sistema/apresentacao.php>. Diversos acessos. Acesso em: 15 fev. 2017.

TEIXEIRA, M. A. As mudanças agrícolas no Mato Grosso do Sul: o exemplo da grande Dourados. Tese (Doutorado em Geografia Humana). Faculdade de Filosofia, Letras e Ciências Humanas da Universidade de São Paulo. São Paulo, 1989. 